PRODUÇÃO DE BIODIESEL E ANÁLISE DE CROMATOGRAFIA EM PAPEL NO ENSINO DE QUÍMICA ORGÂNICA

\title{
BIODIESEL PRODUCTION AND PAPER CHROMATOGRAPHY IN ORGANIC CHEMISTRY TEACHING
}

\author{
ROCHA, Juliana Almeida ${ }^{1 *}$; ROYO, Vanessa de Andrade ${ }^{2}$; MENEZES, Elytania Veiga ${ }^{3}$ \\ 1,2,3 Universidade Estadual de Montes Claros (UNIMONTES), Programa de Pós-graduação em Biotecnologia, \\ Campus Universitário Professor Darcy Ribeiro, Prédio 7, Sala 206, Vila Mauriceia, cep: 39401-089, Montes \\ Claros - MG, Brasil. \\ (fone: +553832298342 ) \\ * Autor correspondente \\ e-mail: juliana-57@hotmail.com
}

Received 29 May 2016; accepted 16 July 2016

\section{RESUMO}

O biodiesel é uma importante energia renovável que ganha destaque principalmente devido à possível redução das reservas de petróleo e dos impactos ambientais intensificados pelo uso de combustíveis fosseis. Esse biocombustível é produzido a partir de diversas matérias primas oleosas, catalisadores e alcoóis. Gera como subproduto a glicerina, que é utilizada em distintos tipos de indústrias. Diante da importância desse combustível e da necessidade de integrar o conteúdo teórico com a aplicação prática desses conhecimentos, este artigo tem como objetivo descrever um experimento que pode ser utilizado para o ensino de conteúdos como cromatografia e reação de transesterificação em disciplinas da graduação. Para produção de biodiesel foram utilizados: óleo de soja, metanol e hidróxido de potássio, e para análise em cromatografia em papel empregou-se: papel de filtro e os solventes hexano, éter etílico e ácido acético como eluentes. A viscosidade e massa especifica do óleo de soja e do biodiesel foram aferidas. Com esta aula prática os acadêmicos observaram que a reação de transesterificação alterou as propriedades físico-químicas do óleo quando ele foi convertido em biodiesel e compreenderam os princípios básicos que regem as técnicas cromatográficas e reações orgânicas.

Palavras-chave: Biocombustível; viscosidade, Massa específica, Transesterificação

\begin{abstract}
Biodiesel is an important renewable energy that stands out mainly due to the possible reduction of oil reserves and environmental impacts intensified by the use of fossil fuels. This biofuel is produced from various oily materials, catalysts and alcohols. Generates glycerin as a byproduct, which is used in different kinds of industries. Given the importance of the fuel and the need to integrate the theoretical content with the practical application of knowledge, this article aims to describe an experiment that can be used for teaching content such as chromatography and transesterification reaction in graduation courses. For biodiesel production were used: soybean oil, methanol and potassium hydroxide, and analysis on paper chromatography was employed: filter paper and the solvents hexane, ethyl ether and acetic acid as eluants. The viscosity and specific gravity of soybean oil and biodiesel were measured. With experiments the academics observed that the transesterification reaction changes the physical-chemical properties of oil when it is converted into biodiesel and understand basic principles governing the chromatographic techniques and organic reactions.
\end{abstract}

Keywords: Biofuel, Viscosity, Especific mass, Transesterification. 


\section{INTRODUÇÃO}

O petróleo é uma importante fonte de energia, no entanto tem-se buscado combustíveis alternativos, devido o esgotamento de reservas desse combustível fóssil, aumento da demanda energética e preocupação com problemas ambientais. Desta forma combustíveis provenientes de biomassa como o etanol e o biodiesel ganharam destaque (lbeto et al., 2012; Marques et al., 2011).

Atualmente muitos países têm estimulado a produção e uso do biodiesel, devido ser um combustível sustentável. Esta sustentabilidade baseia-se na versatilidade de poder produzi-lo a partir de diversas matérias primas como: óleos de soja, palma, girassol, algodão, óleos utilizados no preparo de frituras, gordura de origem animal, rejeitos provenientes do refino e tratamento de efluentes, e ainda a partir de microalgas geneticamente modificadas (Meneghetti et al., 2013; Pereira et al., 2012).

O biodiesel é definido pela Agência Nacional de Petróleo, Gás Natural e Biocombustíveis como combustível composto por alquil ésteres de ácidos graxos de cadeia longa, obtidos por reação de transesterificação, que pode ser combinado ao diesel de petróleo em diversas proporções para ser usado em motores de combustão interna (Brasil, 2005).

Para ser transformado em biodiesel o óleo deve passar por modificações químicas, que podem ocorrer por meio de diversos processos, como: pirólise, craqueamento catalítico, hidrocraqueamento, eletrocaqueamento, emulsificação com solventes como metanol, etanol ou butanol, esterificação, hidroesterificação e transesterificação (Ramos et al., 2011; Geris et al., 2007).

A reação de transesterificação é a mais utilizada na produção de biodiesel. Essa reação ocorre entre o óleo e um álcool de cadeia curta que tenha apenas uma hidroxila na estrutura química como metanol ou etanol. A reação ocorre em presença de catalisador, que pode ser de caráter: ácido, básico ou enzimático. A produção industrial do biodiesel utiliza principalmente catalisadores básicos como hidróxidos de sódio ou potássio, e o principal álcool empregado é o metanol (Meneghetti et al., 2013; Ramos et al., 2011; Umpierre e Machado, 2013).
Para a transesterificação ter um rendimento satisfatório, é necessário que o óleo e o álcool estejam em uma razão molar adequada. Teoricamente seriam necessários três mols de álcool para reagir com um mol de óleo, mas por se tratar de uma reação reversível para conseguir maior rendimento adiciona álcool em excesso, desta forma ocorre uma maior formação de ésteres (Marques et al., 2011) (Figura 1).

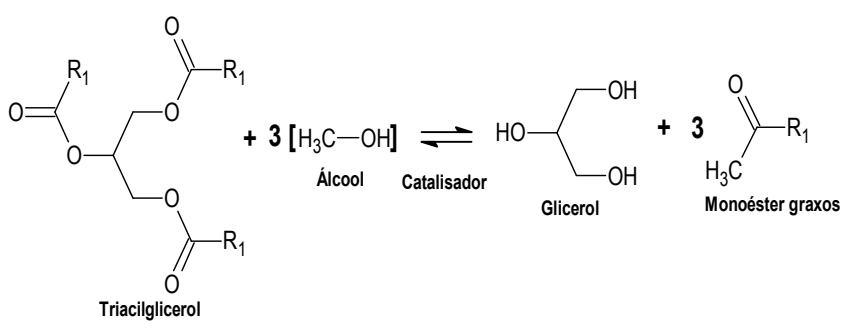

Figura 1. Estequiometria da reação

Acredita-se que nesta reação com catalisador básico inicialmente ocorre formação de uma espécie reativa chamada alcóxido (álcool + catalisador alcalino), que realiza ataque nucleofílico às carbonilas dos acilglicerois, formando um intermediário tetraédrico, que se reorganiza liberando um éster e outro alcóxido, que é desprotonado regenerando a base inicial. Essa reação ocorre em todos os acilglicerois da molécula de triacilglicerol, no final da reação haverá ésteres alquilicos e glicerol (Meneghetti et al., 2013; Ramos et al., 2011).

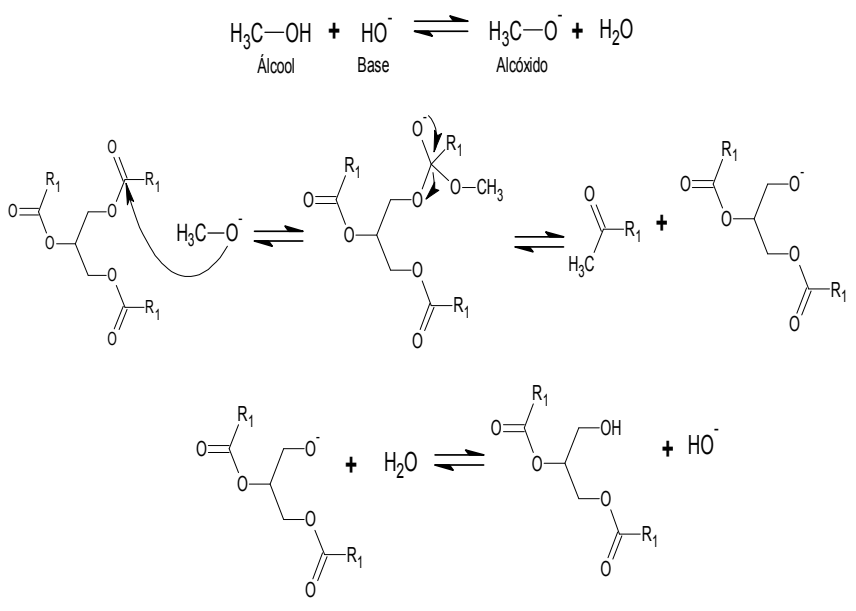

Figura 2. Reação de transesterificação

PERIÓDICO TCHÊ QUÍMICA • www.periodico.tchequimica.com • Vol. 13 N. 26 - ISSN 1806-0374 (impresso) • ISSN 1806-9827 (CD-ROM) • ISSN 2179-0302 (meio eletrônico) 
O glicerol é um subproduto da reação de transesterificação. Após passar por processos de purificação, para remover: catalisador, álcool e óleo não reagidos, água, sabões e sais, ele pode ser utilizado em diversas indústrias (cosmética, química, farmacêutica, de alimentos, têxtil, tintas, resinas e poliésteres) (Marques et al., 2011; Umpierre e Machado, 2013; Lopes et al., 2014).

Durante a produção do biodiesel é possível monitorar o progresso da reação usando técnicas cromatográficas (Geris et al., 2007; Ferrari et al., 2005; Froehner et al., 2007). A cromatografia é um método físico-químico de separação, em que os compostos de uma mistura interagem com uma fase móvel e uma estacionária. Os diferentes níveis de interação deles com essas duas fases determinam a migração diferencial dos analitos levando à separação deles (Degani et al., 1988).

Há grande variedade de fases móveis e estacionárias que podem ser utilizadas. Isso faz com que essa técnica seja muito versátil e possa ser utilizada em diversas situações. De acordo com a natureza dessas fases, modo de separação dos componentes e suporte utilizado essa técnica pode ser classificada em cromatografia em coluna ou cromatografia planar (Degani et al., 1988; Collins et al., 2006).

$\mathrm{Na}$ cromatografia planar a fase estacionária fica em um suporte plano e a fase móvel é sempre um líquido, que pode ser apenas um solvente ou um conjunto de solventes combinados em diferentes proporções. É um método rápido que geralmente tem menor custo do que as técnicas de cromatografia em coluna. Pode ser empregada na análise qualitativa de uma ou mais substâncias e pode auxiliar em processos de purificação de substâncias. Um parâmetro importante na cromatografia planar é o fator de retenção (Rf), esse fator é a distância ou o espaço de eluição do analito. E o que determina o Rf e uma melhor separação dos compostos é basicamente a maior ou menor afinidade entre as substâncias da mistura, com a fase estacionária e a fase móvel (Collins et al., 2006; Ribeiro et al., 2015).

Após separação cromatográfica, a identificação das substâncias incolores pode ser feita por meio do uso de reveladores. As técnicas podem ser destrutivas (revelação química) ou não (revelação física), e algumas ainda podem orientar quanto uma possível identidade do composto. Entre os diversos tipos de reveladores podem ser citados: luz ultravioleta (365 nm), anisaldeído, iodo, vanilina sulfúrica, DNFH $(2,4-$ dinitrofenil-hidrazina), NP/PEG (2-aminoethyl diphenylborinate + polietilenoglicol), reativo de Dragendorff, cloreto férrico (Ribeiro et al., 2015; Barbosa et al., 2004; Alves et al., 2011).

A cromatografia em papel (CP) marcou o inicio da cromatografia planar, que ocorreu na metade do século XIX. A partir dela desenvolveram-se técnicas cromatográficas mais eficientes como a cromatografia em camada delgada, cromatografia em camada delgada de alta eficiência e a cromatografia em camada delgada de ultraeficiência (Collins, 2010). Desta forma a técnica de $\mathrm{CP}$, que tem um baixo custo, por utilizar materiais simples, é uma opção para aula prática para acadêmicos de graduação sobre fundamentos da técnica de cromatografia.

\section{MATERIAL E MÉTODOS}

A aula foi realizada com acadêmicos do $6^{\circ}$ período do curso bacharelado em Ciências biológicas com ênfase em biotecnologia, da Universidade Estadual de Montes Claros, em duas partes. Na primeira etapa realizaram-se os cálculos dos reagentes, aferiu-se a massa específica e viscosidade do óleo e procedeu-se a transesterificação e purificação do biodiesel. $\mathrm{Na}$ segunda etapa ocorreu a análise de cromatografia em papel, cálculo do fator de retenção (Rf) e aferição de massa específica e viscosidade do biodiesel. Foram utilizados reagentes: metanol (Dinâmica ${ }^{\circledR}$ ), hidróxido de potássio (Dinâmica $\AA$ ), hexano (Vetec $\AA)$, éter etílico (Dinâmica $\left.{ }^{\circledR}\right)$, ácido acético (Anidrol®), iodo (Vetec®), papel de filtro e óleo de soja (adquirido em supermercado).

\subsection{Produção do Biodiesel}

Ocorreu por meio de transesterificação básica. A matéria prima foi o óleo de soja, metanol e o catalisador hidróxido de potássio. Inicialmente realizou-se o cálculo dos reagentes, na razão molar de 6 mols de álcool para $1 \mathrm{~mol}$ de óleo e catalisador $1,5 \%$ da massa de óleo. Inicialmente preparou-se o metóxido de potássio dissolvendo o hidróxido de potássio no metanol. Logo após verteu-se o óleo no metóxido de potássio e levou-se para aquecer sob refluxo em banho com aquecedor e agitador magnético por 
30 minutos à $45^{\circ} \mathrm{C}\left( \pm 2{ }^{\circ} \mathrm{C}\right)$ (Figura $\left.3 \mathrm{~A}\right)$. Após a reação transferiu-se 0 material para funil de separação e deixou-se em repouso para decantar a glicerina (Figura 3B). Após remoção da glicerina o biodiesel foi lavado com água destilada a $\pm 80^{\circ} \mathrm{C}$ e após cada lavagem a água foi testada com fenolftaleína até observar que ela não estava mais com pH básico. Para finalizar o processo o biodiesel lavado foi colocado em estufa (Nova Ética, modelo 400-4ND) a $100{ }^{\circ} \mathrm{C}$ até desaparecer todo vestígio de água e turbidez (Ferrari et al., 2005; Froehner et al., 2007; Pierezan et al., 2015; Santos et al., 2013).

\subsection{Análise de cromatografia em papel}

Utilizou-se papel de filtro $(10 \mathrm{~cm} \times 3 \mathrm{~cm})$ como suporte para corrida cromatográfica. Com auxílio de um capilar aplicou-se no papel de filtro (0,5 $\mathrm{cm}$ da extremidade inferior) a amostra do óleo (matéria prima) e do biodiesel (produto obtido) e colocou-se em cuba para ocorrer a eluição com a fase móvel na razão v/v: hexano: éter etílico: acido acético (80:20:1) (Figura 3C). Após eluição as placas foram reveladas em câmara com iodo PA (Figura 3D). E calcularamse os fatores de retenção (Rf) para o óleo e para o biodiesel.

\subsection{Massa específica e viscosidade}

A massa especifica foi medida por picnometria a $20{ }^{\circ} \mathrm{C} \pm 2{ }^{\circ} \mathrm{C}$ (Figura 3E). A viscosidade foi aferida em copo Ford a $20{ }^{\circ} \mathrm{C}$ para o óleo de soja e a $40^{\circ} \mathrm{C}$ para o biodiesel produzido (Figura 3F). Conforme metodologia do Instituto Adolfo Lutz, 2008.

\section{RESULTADOS E DISCUSSÃO}

$\mathrm{Na}$ análise de CP foi possível verificar que óleo e biodiesel percorreram diferentes distâncias na corrida cromatográfica (Figura 3G). Esse fato refletiu no valor do Rf da amostra de óleo $(0,77)$ e do biodiesel $(0,89)$ (Tabela 1$)$. Com base nestes valores foi possível demonstrar para os acadêmicos que com a reação de transesterificação ocorreu redução no tamanho da molécula, pois o triacilglicerol (óleo) liberou três moléculas de ácidos graxos na forma de ésteres metílicos. Além disso esses ésteres passaram a ter características de polaridade diferenciadas, devido terem recebido em suas estruturas um radical metil proveniente do álcool (metanol). E esses fatores levaram essa duas amostras a terem polaridades distintas o que refletiu em diferentes valores de $\mathrm{Rf}$ em uma corrida em que utilizou o mesmo eluente para as duas amostras.

Tabela 1. Fator de retenção, viscosidade e massa especifica aferidas para óleo e biodiesel.

\begin{tabular}{l|l|l}
\hline \multicolumn{1}{c|}{ Parâmetro } & \multicolumn{1}{|c|}{$\begin{array}{c}\text { Óleo } \\
\text { de soja }\end{array}$} & \multicolumn{1}{|c}{$\begin{array}{c}\text { Biodiese } \\
\text { I }\end{array}$} \\
\hline Fator de retenção & 0,77 & 0,89 \\
Viscosidade $\left(\mathrm{mm}^{2} \cdot \mathrm{s}^{-1}\right)$ & 63,81 & 4,0 \\
Massa específica $\left(\mathrm{g} \cdot \mathrm{cm}^{-3}\right)$ & 0,9231 & 0,8901 \\
\hline
\end{tabular}

A viscosidade e a massa específica são parâmetros determinados pelas características físico-químicas dos ácidos graxos que compõe a amostra, como tamanho das cadeias e quantidade de ligações insaturadas. A viscosidade tende a elevar-se conforme aumenta o tamanho da cadeia carbônica e reduz o número de ligações insaturadas e ainda sofre influência da temperatura a que o material está exposto. Já a massa específica aumenta conforme maior comprimento da cadeia carbônica e com a redução do número de ligações insaturadas. A presença de impurezas no biodiesel pode afetar o valor de massa específica (Yilmaz, 2011; Lôpo et al., 2009).

A viscosidade do óleo de soja $(63,81$ $\mathrm{mm}^{2} . \mathrm{s}^{-1}$ ) foi superior a aferida para o biodiesel $\left(4,0 \mathrm{~mm}^{2} \cdot \mathrm{s}^{-1}\right)$ (Tabela 1). Um dos objetivos da transesterificação é reduzir a viscosidade do óleo para poder ser usado como combustível. Isso é importante devido alta viscosidade no combustível favorecer combustão incompleta e formação de depósitos nos injetores de combustível, e em consequência pode levar a avarias no motor (Geris et al., 2007). Portanto aferindo a viscosidade do óleo e do biodiesel os alunos puderam visualizar que a reação de transesterificação consegue atingir este objetivo.

A massa especifica do óleo $\left(0,9231 \mathrm{~g} . \mathrm{cm}^{-}\right.$ ${ }^{3}$ ) e a do biodiesel $\left(0,8901 \mathrm{~g} \cdot \mathrm{cm}^{-3}\right)$ permitem observar que a transesterificação também reduziu este parâmetro assim como ocorreu com a viscosidade (Tabela 1). Aferição de massa específica pode ser utilizada como ferramenta para monitorar a pureza do biodiesel. Pois se existirem resquícios de glicerina ou de ácidos graxos não reagidos no biodiesel devido 
problemas no processo de purificação, haverá alteração da massa específica (Froehner et al., 2007).

\subsection{Aplicação em aula}

O ensino de ciências como a química a cada dia torna-se mais complexo. Esse fato exige do docente a capacidade de desenvolver estratégias para tornar o ensino mais atraente para os alunos, e uma das formas de conseguir isso é integrar o conhecimento teórico com algum contexto social (Freitas et al., 2016). O tema biocombustíveis é constantemente abordado na mídia, portanto o experimento é atraente para o estudante, na perspectiva de se aprender como esse combustível é produzido.

Algumas técnicas cromatográficas podem ter preço elevado o que dificulta a demonstração prática delas para alunos de cursos de graduação. Assim o experimento apresentado neste trabalho é uma opção para promover o contato dos acadêmicos com os fundamentos da cromatografia, utilizando materiais simples. Ao mesmo tempo eles têm a oportunidade de presenciar uma utilidade real deste procedimento, o que facilita a compreensão da importância da técnica e da sua aplicação em várias outras atividades. Esse experimento também pode ser utilizado para iniciar o ensino de conteúdo de reações orgânicas.

Esse experimento propiciou ainda o desenvolvimento e debate de outros assuntos pertinentes à ampliação do senso crítico dos acadêmicos, como a importância de utilizar fontes energéticas renováveis, discutindo sobre outros tipos de energia sustentáveis, impacto que a produção agrícola voltada para produção de biodiesel pode trazer para fornecimento de alimentos, impactos ambientais, entre outros. Após a aula foi proposta uma atividade, em que se propuseram questões sobre os conceitos discutidos em aula. Através dessa atividade foi possível verificar que os estudantes entenderam a importância e aplicação desses conhecimentos.

\section{CONCLUSÕES}

Nesta aula foi possível associar três conteúdos de grande importância para a biotecnologia, que são a produção de biocombustíveis, introdução a reações orgânicas e a cromatografia que é um método analítico de extrema importância para várias áreas. Permitiu ainda discutir com alunos questões envolvendo biocombustíveis em geral, a importância como fonte energética, as diversas matérias primas usadas na produção, importância de buscar outras matérias primas que não representem fontes de alimentos e também questões relacionadas a cromatografia como os tipos de cromatografias, fases estacionárias e móveis, fundamentos básicos da técnica, outras análises que poderiam ser realizadas para confirmar a formação dos ésteres graxos, a importância dos métodos de identificação que são associados a cromatografia, além de iniciar à discussão sobre os mecanismos e tipos de reações orgânicas.

\section{AGRADECIMENTOS}

Ao Programa de Pós-graduação em Biotecnologia. Aos alunos do curso de graduação em Ciências Biológicas - Ênfase em Biotecnologia e à Universidade Estadual de Montes Claros (UNIMONTES).

\section{REFERÊNCIAS:}

1. Alves, M. M.; Pereira, A. M. S.; Pereira, P. S.; França, S. C.; Bertoni, B. W.. Sci Plena, 2011, 7, 1. Disponível em: http://www.scientiaplena.org.br/sp/article/view File/159/389

2. Barbosa, W. L. R.; Quignard, E.; Tavares, I. C. C.; Pinto, L. N.; Oliveira, F. Q.; Oliveira, R. M. Revista Científica da UFPA, 2004, 4. Disponível em: http://www2.ufpa.br/rcientifica/didaticos cienti ficos/pdf textos/abord fitoquimica.pdf

3. Brasil. Lei $\mathrm{N}^{\circ} 11.097$ de 13 de Janeiro de 2005. Dispõe sobre a introdução do biodiesel na matriz energética brasileira; altera as Leis nos 9.478, de 6 de agosto de 1997, 9.847, de 26 de outubro de 1999 e 10.636, de 30 de dezembro de 2002; e dá outras providências. Diário Oficial da União, 13 de Janeiro de 2005. Brasília. Disponível em: http://www.planalto.gov.br/ccivil_03/_ato20042006/2005/Lei/L11097.htm

4. Collins, C. H. Sci. Chromatographica, 2010, 2, $50 . \quad$ Disponível em: http://www.scientiachromatographica.com/arti

PERIÓDICO TCHÊ QUÍMICA • www.periodico.tchequimica.com • Vol. 13 N. 26 - ISSN 1806-0374 (impresso) • ISSN 1806-9827 (CD-ROM) • ISSN 2179-0302 (meio eletrônico) 
cle/537a12041ef1faac47000000

5. Collins, C. H.; Braga, G. L.; Bonato, P. S. Fundamentos de cromatografia. Editora da UNICAMP, Campinas: São Paulo, 2006.

6. Degani, A. L. G.; Cass, Q. B.; Vieira, P. C. Quím. Nova na Escola, 1988, 7. Disponível em:

http://qnesc.sbq.org.br/online/qnesc07/atual.p df

7. Ferrari, R. A.; Oliveira, V. S.; Scabio, A. Quím. Nova, 2005, 28, 19. http://dx.doi.org/10.1590/S010040422005000100004

8. Froehner, S.; Leithold, J.; Lima Júnior, L. F. Quím. Nova, 2007, 30, 2016. http://dx.doi.org/10.1590/S010040422007000800037

9. Freitas, T. L.; Da Costa, M. A.; Freitas, F. C. R. M.; Oliveira, T. F.; Moraes, L. M.; Field's, K. A. P.; Rezende, G. A. A.; Santos, R. G. Periódico Tchê Química, 2016, 13, 25.

10. Geris, R.; Santos, N. A. C.; Amaral, B. A.; Maia, I. S.; Castro, V. D.; Carvalho, J. R. M. Quím. Nova, 2007, 30, 1369. http://dx.doi.org/10.1590/S010040422007000500053

11. Ibeto, C.N.; Okoye, C.O.B.; Ofoeffule, A.U.O. ISRN Renew Energ, 2012, 1. http://dx.doi.org/10.5402/2012/621518

12. Instituto Adolfo Lutz. Métodos FísicoQuímicos para Análise de Alimentos - $1^{\text {a }}$ Edição Digital. 2008. Disponível em: http://www.ial.sp.gov.br/index.php? option $=$ com remository\&ltemid $=0 \&$ func $=$ sele ct\&id=1\&orderby=1\&page $=1$

13. Lopes, A. P.; Canesin, E. A.; Suzuki, R. M.; Tonin, L. T. D.; Palioto, G. F.; Seixas, F. L. Rev Virtual Quím, 2014, 6, 1564. http://dx.doi.org/10.5935/19846835.20140102

14. Lôpo, I. P.; Ferreira, S. L. C.; Cruz, R.S. Quím. Nova, 2009, 32, 1596. http://dx.doi.org/10.1590/S010040422009000600044
15. Marques, E. P.; Silva, V. D. da; Almeida, J. de M. S.; Costa, H. D.; Cavalcante, G. H. R.; Marques, A. L. B. Cadernos de Pesquisa (UFMA), 2011, 18, 70. Disponível em: http://www.periodicoseletronicos.ufma.br/inde x.php/cadernosdepesquisa/article/view/744

16. Meneghetti, S. M. P.; Meneghetti, M. R.; Brito, Y. C.. Rev. Virtual Quím, 2013, 5, 63. http://dx.doi.org/10.5935/19846835.20130007

17. Pereira, C. M. P.; Hubuss, C. B.; Maciel, J. V.; Ferreira, L. R.; Del Pino, F. B.; Mesko, M. F.. Quím Nova, 2012, 35, 2013. http://dx.doi.org/10.1590/S010040422012001000022

18. Pierezan, L.; Cabral, M. R. P.; Martins Neto, D.; Stropa, J.M.; Oliveira, L. C. S.; Scharf, D. R.; Simionatto, E.L.; Silva, R.C.L.; Simionatto, E.. Quím. Nova, 2015, 38, 328. http://dx.doi.org/10.5935/01004042.20150018

19. Ramos, L. P.; Silva, F. R.; Mangrich, A. S.; Cordeiro, C. S.. Rev. Virtual Quím, 2011, 3, $385 . \quad$ http://dx.doi.org/10.5935/19846835.20110043

20. Ribeiro, C. M. R.; Valverde, A. L.; Ribeiro, M. M. J.; Souza, T. S. G.; Fagundes, T. S. F.; Bittencourt, L. B.; Dutra, K. D. B.; Epifanio, R. A.. Rev. Virtual Quím, 2015, 7, 1030. http://dx.doi.org/10.5935/19846835.20150056

21. Santos, R. C. R.; Vieira, R.B.; Valentini, A. Microchem J, 2013, 109, 46. http://dx.doi.org/10.1016/j.microc.2012.05.001

22. Umpierre, A. P.; Machado, F.. Rev. Virtual Quím, 2013, 5, 106. http://dx.doi.org/10.5935/19846835.20130010

23. Yilmaz, N.. Biomass Bioenerg, 2011, 35, 2936.

http://dx.doi.org/10.1016/j.biombioe.2011.03.0 $\underline{26}$ 

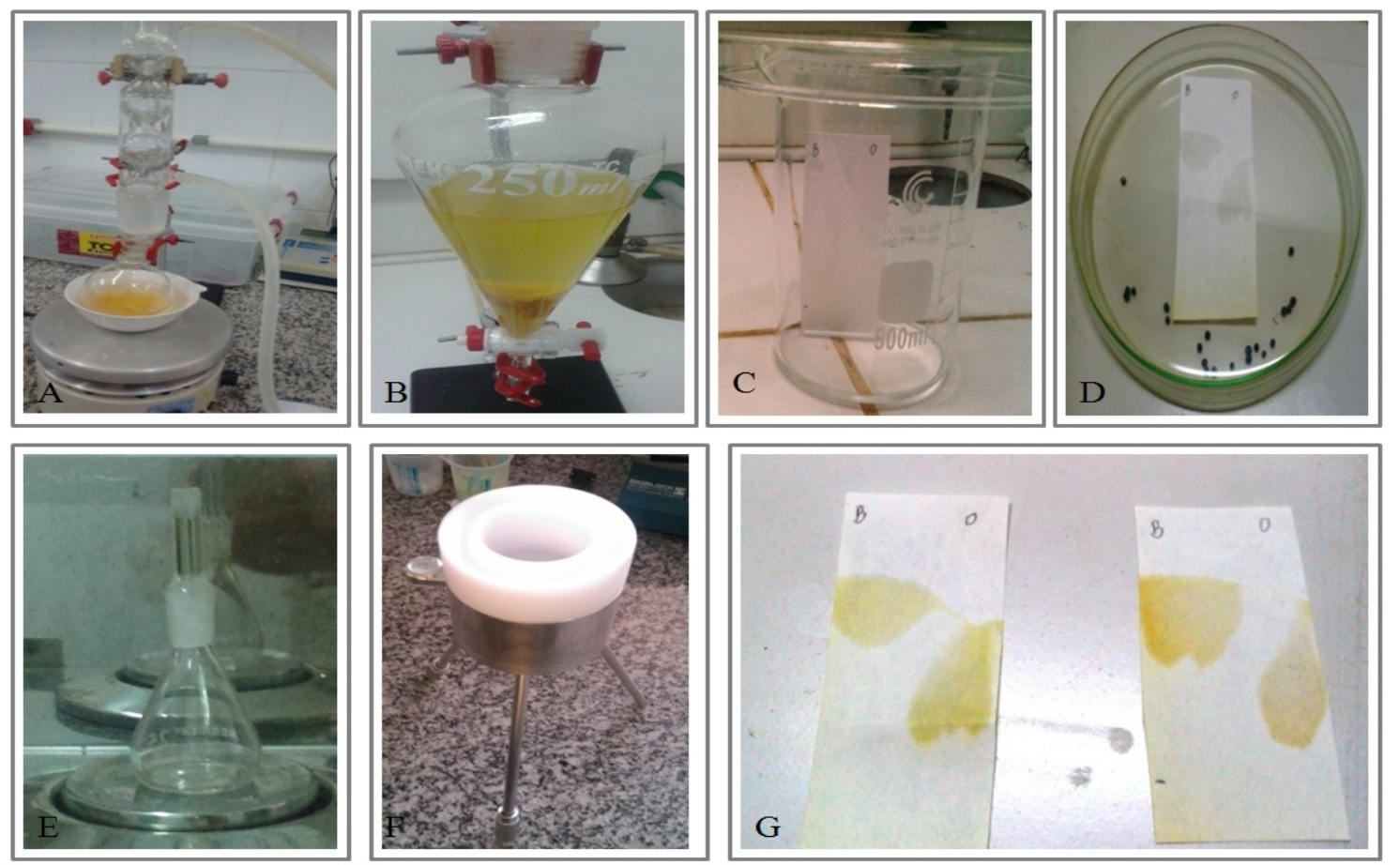

Figura $3 A$ - G. Fig. A - Transesterificação; Fig. B - Separação biodiesel e glicerina por decantação; Fig. C - Eluição CP das amostras óleo (à direita) e biodiesel (à esquerda); Fig. D - Revelação CP em câmara com iodo; Fig. E - Aferição massa específica; Fig. F-Aferição da viscosidade; Fig. G CP após revelação com iodo.

PERIÓDICO TCHÊ QUÍMICA • www.periodico.tchequimica.com • Vol. 13 N. 26.

•ISSN 1806-0374 (impresso) • ISSN 1806-9827 (CD-ROM) • ISSN 2179-0302 (meio eletrônico)

(C) 2016. Porto Alegre, RS. Brasil

The Periódico Tchê Química (ISSN: 1806-0374; 2179-0302) is an open-access journal since 2004. Journal DOI: 10.52571/PTQ. http://www.tchequimica.com. This text was introduced in this file in 2021 for compliance reasons.

() The Author(s)

OPEN ACCESS. This article is licensed under a Creative Commons Attribution 4.0 (CC BY 4.0) International License, which permits use, sharing, adaptation, distribution, and reproduction in any medium or format, as long as you give appropriate credit to the original author(s) and the source, provide a link to the Creative Commons license, and indicate if changes were made. The images or other third-party material in this article are included in the or exceeds the permitted use, you will need to obtain permission directly from the copyright holder. To view a copy of this license, visit http://creativecommons.org/licenses/by/4.0/. 